\title{
Effect of particle concentration and temperature on the thermo-physical properties of ethylene glycol-water mixture based boron nitride nanofluids
}

\author{
Monisha Michael $^{1} \cdot$ Aparna Zagabathuni $^{2}$-S. K. Pabi ${ }^{3} \cdot$ Sudipto Ghosh ${ }^{1}$
}

Received: 3 February 2020 / Accepted: 27 August 2020 / Published online: 31 August 2020

(c) Springer Nature Switzerland AG 2020

\begin{abstract}
Present article focusses on the thermal and rheological characteristics of ethylene glycol-water mixture (volume $=60 / 40$ ) based boron nitride ( $h$-BN) nanofluids measured at different volume concentrations $(0.5-2$ vol\% $h$-BN) between temperatures $30-60^{\circ} \mathrm{C}$. X-ray diffraction and TEM analysis have confirmed the hexagonal structure of $h$-BN nanoparticles and the size range of the nanoparticles is within $90-170 \mathrm{~nm}$. To optimize the ultrasonication time, the thermal conductivity of $h$-BN nanofluids has been monitored after each $30 \mathrm{~min}$ of sonication until a maximum thermal conductivity increase is achieved. The thermal conductivity of $h$-BN nanofluids shows an increasing trend with respect to particle concentration. Also, the thermal conductivity enhancement exhibits a temperature independent nature. The viscosity studies carried out over a shear rate of $0.612-122 \mathrm{~s}^{-1}$ revealed an increasing trend with the increasing concentration of $h$-BN loading. For all the volume concentrations, at lower shear rates, the viscosity initially decreased, displaying a non-Newtonian nature, and with a further increase in shear rate, the viscosity stays constant exhibiting a Newtonian nature. Based on the experimental outcomes, a correlation is introduced. The correlation showed a strong agreement with the current results, with an $R^{2}$ value of 0.99 .
\end{abstract}

Keywords Nanofluids · Boron nitride nanoparticles · Ethylene glycol-water mixture · Thermal conductivity · Viscosity

\section{Introduction}

Nanofluids are an alternative to the already available conventional heat transfer fluids viz., ethylene glycol, water, etc. Nanoparticles dispersed in heat transfer fluids (nanofluids) have dramatically improved its thermo-physical properties relative to conventional fluids. Therefore, these nanofluids find their application in different heat transfer sectors, industrial units, and microelectronics. Over the decades, numerous works on the thermo-physical properties of different nanofluids viz., $\mathrm{Al}_{2} \mathrm{O}_{3}$ [1], $\mathrm{Cu}$ [2], MWCNT [3], etc., have come up. Researchers have also attempted to study with different base fluids like oils [4], lubricants
[5], kerosene [6], etc. It is found that throughout cold areas, such as Antarctica, the United States of America, Canada, and other subarctic countries, large quantities of energy are spent on heating residential and industrial buildings as the air temperature can routinely exceed $-40^{\circ} \mathrm{C}$ during the winter. In this manner, it is a typical practice to utilize propylene glycol or ethylene glycol combined with water in varying amounts as a heat transfer fluid to bring down the freezing point of water. The heat transfer properties of coolants like these can be further enhanced by dispersing suitable nanoparticles, viz., nanofluids. Hamid et al. [7] worked with nanofluids having varying mixture ratios $(20: 80,40: 60,50: 50,60: 40$, and 80:20 (W/EG)) of

$\triangle$ Monisha Michael, michael.monisha@gmail.com | ${ }^{1}$ Department of Metallurgical and Materials Engineering, Indian Institute of Technology Kharagpur, Kharagpur, West Bengal 721302, India. ${ }^{2}$ Department of Mechanical Engineering, Indian Institute of Technology Guwahati, Guwahati, Assam 781039, India. ${ }^{3}$ School of Engineering and Technology, Adamas University, Barasat, West Bengal 700126, India. 
$\mathrm{TiO}_{2}-\mathrm{SiO}_{2}$ for 1 vol\% and studied their thermo-physical properties. Their results suggested good heat transfer properties for 40:60 and 80:20 (W/EG) based $\mathrm{TiO}_{2}-\mathrm{SiO}_{2}$ nanofluids. Guo et al. [8] prepared various mixture ratios (0-100\%) of ethylene glycol-water based $\mathrm{SiO}_{2}$ nanofluids. Their results concluded that the percentage of ethylene glycol content shows a great effect on the thermal conductivity (TC) of $\mathrm{SiO}_{2}$ nanofluids. Namburu et al. [9] studied the rheological properties of $\mathrm{CuO}$ nanoparticles suspended in the EG/W (40/60) mixture. They observed an increment in the viscosity with an increase in the particle concentration and decrement with a rise in temperature in the range of $35-50{ }^{\circ} \mathrm{C}$. The $\mathrm{TC}$ of $\mathrm{Fe}_{3} \mathrm{O}_{4}$ nanofluid with ethylene glycol-water mixture of three different volumetric ratios (20:80, 40:60, and 60:40) was studied by Sundar et al. [10]. At $60{ }^{\circ} \mathrm{C}$, a TC enhancement of $46 \%$ for a $2 \%$ volume fraction was observed for 20:80 EG/W based nanofluid. They have also proposed a correlation that estimates the $\mathrm{TC}$ of $\mathrm{Fe}_{3} \mathrm{O}_{4}$ nanofluid for all the three ratios of EG/W mixture. Ramachandran et al. [11] measured the thermophysical properties of nano-cellulose nanofluids having EG/W (60/40) as the base fluid. The nanofluid showed a maximum TC increment of $9.05 \%$ over the base fluid for 1.3 vol\% nano-cellulose. The viscosity also showed an increment with increasing particle concentration and the maximum increment in the viscosity was observed to be $4.16 \%$ for 1.3 vol\% nano-cellulose. Yiamsawas et al. [12] also investigated the viscosity of EG/W (80/20) based $\mathrm{Al}_{2} \mathrm{O}_{3}$ and $\mathrm{TiO}_{2}$ nanofluid. Eshgarf et al. [13] showed that $\mathrm{SiO}_{2} /$ CNT- EG/W hybrid nanofluids displayed a non-Newtonian nature even though the base fluids showed a Newtonian nature. Bahrami et al. [14] also commented on the nature of Fe-CuO EG/W hybrid nanofluid. They observed that as the nanoparticle concentration increased in the nanofluid, the fluid behavior changed from Newtonian to non-Newtonian.

Boron nitride $(\mathrm{BN})$ is a ceramic material with remarkable properties like wide bandgap, superb mechanical properties, and marked chemical inertness. BN is known to exist in different crystal forms. The most stable form is the hexagonal $\mathrm{BN}(h-\mathrm{BN})$, having a layered structure similar to graphite. Moreover, its main highlight is its insulating property, unlike graphite, with very high TC $\left(\sim 600 \mathrm{~W} \cdot \mathrm{m}^{-1} \mathrm{~K}^{-1}\right)$. Very few literatures is available on the thermo-physical properties of $h$-BN nanofluids. Aqueous boron nitride ( $h$-BN) nanofluids were studied by Han et al. [15]. For 0.1 vol\% $h$-BN, the results showed a TC enhancement of $55 \%$ with good stability. Ilhan et al. [16] also analyzed the heat transfer properties of $h$-BN-water nanofluids. Michael et al. [17] measured the thermo-physical properties of $h$-BN nanofluids having EG and EG/W (40/60) mixture ratio as the base fluid. A TC enhancement as high as $15.5 \%$ with EG as the base fluid and $12.5 \%$ with EG/W (40/60) as the base fluid for 3 vol\% of $h$-BN was reported. The present manuscript also conducts thermo-physical studies on $h$-BN nanofluid but with EG/W 60/40 being used as the base fluid. Although the experimental methodology remains the same as previous work, the TC and viscosity results reveals the importance of the effect of base fluid in present manuscript. Also, EG and EG/W (40/60) mixture are not suitable for extreme cold environment conditions $\left(<-34.4^{\circ} \mathrm{C}\right)$ due to its high freezing point. So, it is highly required to prepare a nanofluid by selectively choosing suitable base fluids like EG/W 60/40 that can effectively be applicable as a heat transfer fluid in extreme cold climate regions.

The present work, therefore, investigates the thermophysical properties of EG/W (60/40) based $h$-BN nanofluids. From the results, it can be said that $h$-BN nanofluids with EG/W (60/40) as base fluid showed improved thermal properties making it a potential substitute to the conventional heat transfer fluids used, especially in extreme climate regions.

The manuscript is designed as follows: the introduction gives a brief review of thermo-physical properties of various nanofluids dispersed in different mixtures of ethylene glycol and water. Section 2 describes the experimental details of the nanomaterial used for the synthesis of nanofluid and its synthesis procedure. Various characterization methods used for the analysis are also discussed. The characterization results and thermo-physical properties obtained are detailed in Sect. 3. Sections 4 and 5 follow the comparison of the present results with estimations from already developed theoretical models and its analysis and the development of a correlation for predicting the thermo-physical properties of $h$-BN nanofluids. Finally, the conclusions made from the results are briefed in Sect. 6.

\section{Materials and method}

\subsection{Materials}

The $h$-BN nanopowder was commercially procured from Sisco Research Laboratories (SRL), Pvt. Ltd., India. For improving the stability of synthesized $h$-BN nanofluids, Polyvinylpyrrolidone (PVP) having a molecular weight of 10,000 was purchased from Sigma Aldrich. Ethylene glycol (EG), having a purity of $99.9 \%$ AR grade obtained from Merck, India, was utilized as a base fluid in the water-EG mixture. Distilled water was used in the whole synthesis process. No further purification was performed on all the obtained chemicals. 


\subsection{Nanofluid synthesis}

The most extensively followed synthesis process for nanofluids viz., the two step method, is used in the present work for the synthesis of $h$-BN nanofluids. The ethylene glycol-water mixture (EG/W) is primarily prepared by carefully mixing water and ethylene glycol in a volumetric ratio of 60:40. PVP, which serves as a surfactant, is added to the base fluid with the aid of magnetic stirring until a homogeneous solution is achieved. The appropriate concentration of $h$-BN nanopowder calculated from Eq. 1 is added to the homogeneous base fluid surfactant mixture, and magnetic stirring has been carried for two hours at 680 RPM. Lastly, the $h$-BN nanofluid is subjected to intense sonication (IMECO ultrasonics water bath, $120 \mathrm{~W}$ ) for a total time period of $4 \mathrm{~h}$. The process of obtaining the optimum sonication time is detailed in Sect. 3. To avoid excess heating during ultrasonication, the water is changed at regular intervals. $h$-BN nanofluids with different concentrations ranging from 0.5 to 2 vol\% were prepared in an above-mentioned manner for TC and viscosity characterizations.

$\phi=\frac{\left(\frac{w_{B N}}{\rho_{B N}}\right)}{\left(\frac{w_{B N}}{\rho_{B N}}+\frac{w_{b f}}{\rho_{b f}}\right)} \times 100$

here $w_{B N}$ and $w_{b f}$ denotes the weight of $h$-BN nanoparticles and base fluid in $g_{1} \rho_{B N}$ and $\rho_{b f}$ denotes the density of $h$-BN nanoparticles and base fluid in $\mathrm{g} \cdot \mathrm{cm}^{-3}$.

The TC and viscosity measurements are carried out by collecting the required amount from the top part of the synthesized nanofluid, after attaining a steady state condition.

\subsection{Characterization of nanofluids}

To confirm the structural properties of $h$-BN nanoparticles, X-ray diffraction (XRD) analysis has been conducted using a BRUKER D8 Advance X-ray diffractometer with $\mathrm{Cu}-\mathrm{Ka}$ radiation. Nanoparticle size and morphology have been analyzed using a Focused lon Beam Scanning Electron Microscope (CARL ZEISS) and Transmission Electron Microscope (JEOL, Japan).

\subsubsection{Thermal conductivity measurement}

The equipment LAMBDA from Flucon fluid control $\mathrm{GmbH}$, which operates on the concept of transient hotwire (THW), is used here to test the TC of $h$-BN nanofluids. The nanofluid sample is poured in a cylindrical vial (length $=90 \mathrm{~mm}$; diameter $=35 \mathrm{~mm}$ ) into which a Teflon-coated platinum wire having a diameter of $100 \mu \mathrm{m}$ is immersed. Here, the platinum wire plays the dual role of a heat source and temperature sensor. Initially, thermal equilibrium is maintained surrounding the wire. Applying a voltage to the wire causes a flow of current, and the wire gets heated. On the basis of the rise in temperature taking place across the wire for a given time period, the TC of the nanofluid sample is calculated. The following mathematical model gives the relation between the temperature rise and TC of the fluid [18]:

$\Delta T=\frac{q}{4 \pi k} \ln \frac{4 a t}{r^{2} C}$

Here, $r$ is the radius of platinum wire, $C$ is the Euler's constant, $q$ is the constant heat produced per unit length and unit time and $a$ is the thermal diffusivity.

Then, the thermak conductivity $(k)$ is determined from the slope (c) of the linear part of the plot $\Delta T$ versus $\ln (t)$.

$k=\frac{q}{4 \pi c}$

The THW method gives better accuracy and precise results when compared to other measurement techniques available [19]. Measured TC values had an uncertainty of less than $2 \%$. Julabo oil bath (F12) was used to maintain the specific temperature in the range of $30^{\circ} \mathrm{C}$ to $60^{\circ} \mathrm{C}$. Figure 1 a shows the measured TC of EG/W 60/40 in comparison with the standard values from the ASHRAE handbook [20]. A maximum deviation of $0.7 \%$ was observed within the measured temperature range.

\subsubsection{Viscosity measurement}

Dynamic viscosity of $h$-BN nanofluids of varying particle concentration is measured at different temperatures over the shear rate ranging from 0.612 to $122 \mathrm{~s}^{-1}$ with a viscometer (Brookfield DV-II + Pro). Through the use of a calibration fluid given by Brookfield Engineering Laboratories, the accuracy of the viscometer is tested and then calibrated. From Fig. 1b, a maximum deviation between the measured viscosity and the standard viscosity data from ASHRAE [20] for EG/W 60/40 is 6.3\%. Table 1 lists the parameters of the experimental conditions for thermal conductivity and viscosity of $h$-BN nanofluid.

\section{Results and discussion}

Figure 2a shows the XRD spectrum of $h$-BN nanoparticles displayed in the range of $20^{\circ}-80^{\circ}$. The crystalline peaks indicate the hexagonal structure of $h$-BN nanoparticles (JCPDS card no. 34-0421) without any impurity phase. The average crystallite size calculated using the 

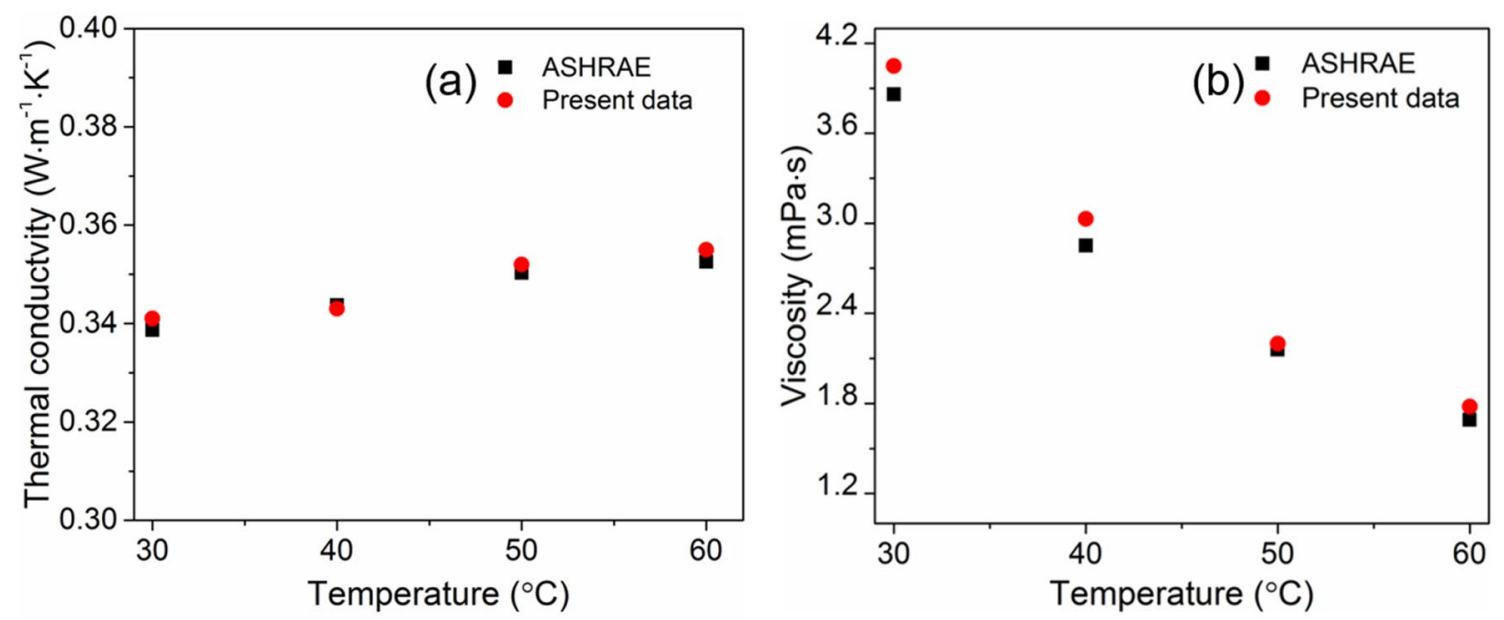

Fig. 1 Measured (a) TC and (b) dynamic viscosity of EG/W 60/40 with respect to standard ASHRAE data

Table 1 Experimental conditions of presented thermal conductivity and viscosity of $h$-BN nanofluid

\begin{tabular}{ll}
\hline Properties & Experimental conditions \\
\hline Thermal conductivity of & a. Average particle size: $100 \mathrm{~nm}$ \\
nanofluids & b. Density of $h-\mathrm{BN}: 2.1 \mathrm{~g} \mathrm{~cm}{ }^{-3}$ \\
& c. $k_{p}: 600 \mathrm{~W} \cdot \mathrm{m}^{-1} \cdot \mathrm{K}^{-1}$ \\
& d. $k_{b f}: 0.33 \mathrm{~W} \cdot \mathrm{m}^{-1} \cdot \mathrm{K}^{-1}$ \\
& e. $h$-BN concentration: $0.5-2 \mathrm{vol} \%$ \\
& f. Temperature: $30-60^{\circ} \mathrm{C}$ \\
& a. $h$-BN concentration: $0.5-2 \mathrm{vol} \%$ \\
Viscosity of nanofluids & b. $\mu_{b f}: 4.2 \mathrm{mPa} \mathrm{s}$ \\
& c. Temperature: $30-60^{\circ} \mathrm{C}$ \\
& d. Shear rate: $0.612-122 \mathrm{~s}^{-1}$ \\
\hline
\end{tabular}

Williamson-Hall method [21] has been estimated to be around $21.2 \mathrm{~nm}$. The morphology and size of $h$-BN nanoparticles analyzed by TEM show almost spherically shaped nanoparticles within the size range of 90-170 nm (Fig. 2b). It is also visible that these nanoparticles form agglomerated structures due to their high surface area.
The ultrasonication time is optimized to achieve a uniform dispersion of $h$-BN nanoparticles in the base fluid. For this purpose, the TC measurement of the $h$-BN nanofluid has been carried out after every $30 \mathrm{~min}$ of sonication. Figure 3 a displays the influence of sonication time on the TC of 0.5 vol\% of $h$-BN nanofluids. It is observed that the TC of $h$-BN nanofluids increases with the increase in the sonication time. The observed increase in TC can be explained as follow: the $h$-BN nanoparticles are in an agglomerated form in the base fluid, immediately after the synthesis, because of its high surface energy. The sonication process, because of its high power, breaks down the agglomerates and attempts to disperse them uniformly in the base fluid. The reducing cluster size of the nanoparticles also increases its Brownian motion. This phenomenon leads to the rise in the TC with the increasing sonication time. The highest TC achieved after 240 min of sonication indicates the maximum dispersion of $h$-BN nanoparticles. Later, this enhancement in the TC of $h$-BN nanofluids starts diminishing. The prolonged
Fig. 2 a XRD patterns, and $\mathbf{b}$ TEM image of $h$-BN nanoparticles
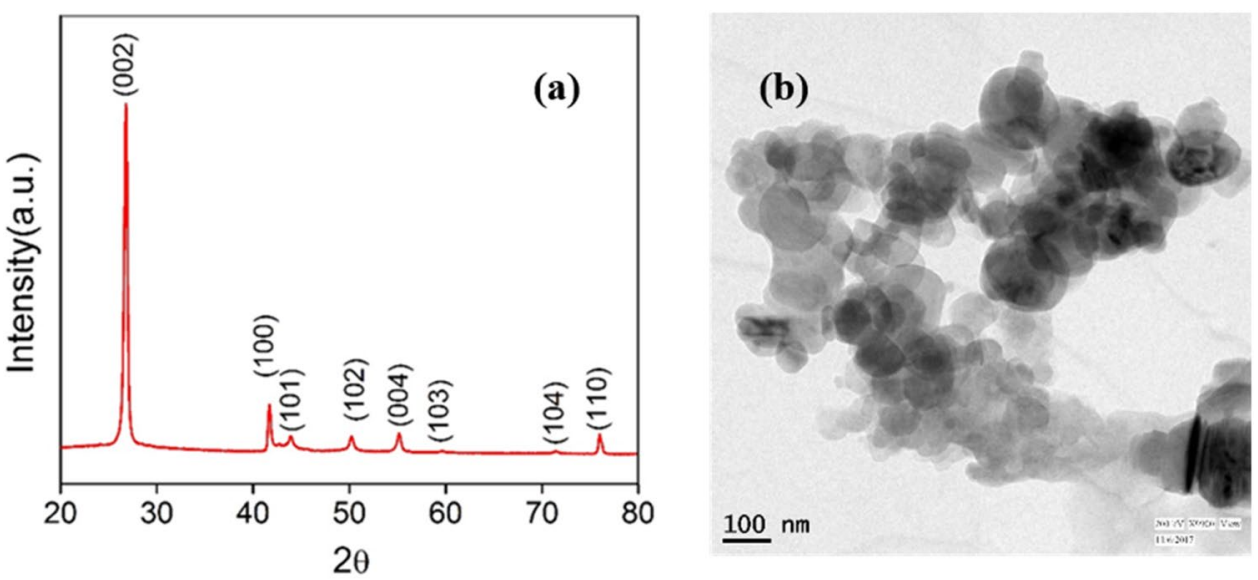

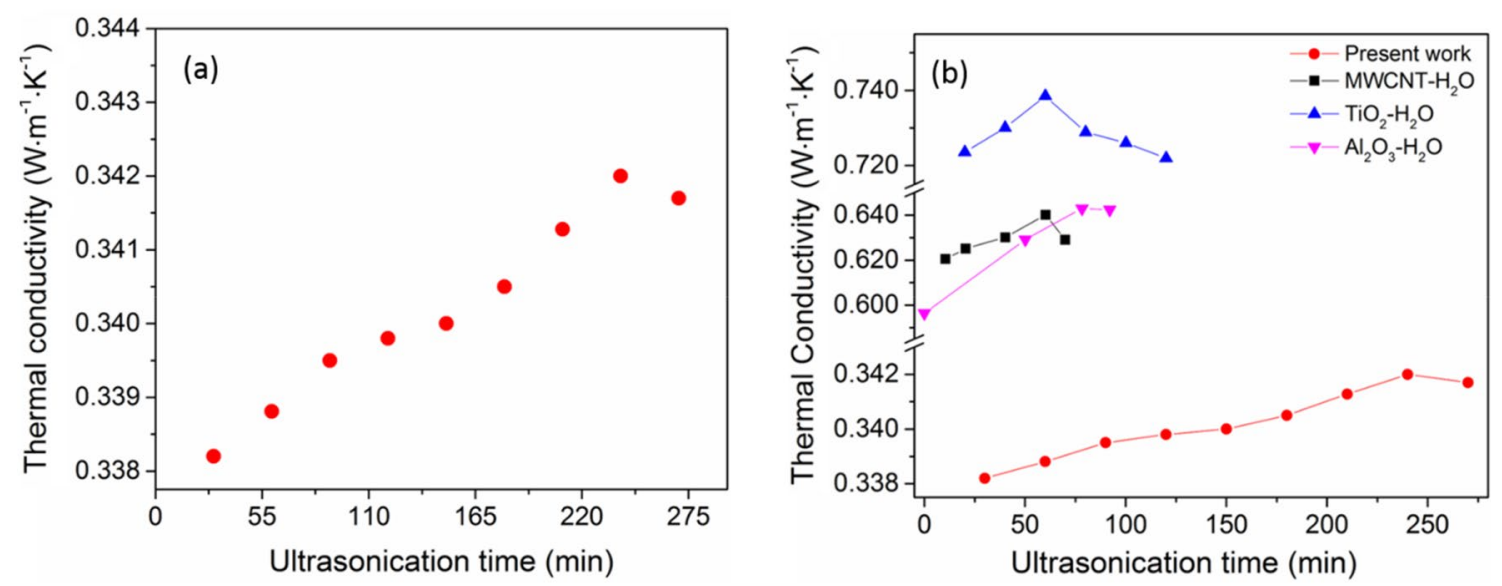

Fig. 3 a Influence of sonication period on TC of 0.5 vol \% $h$-BN nanofluids and $\mathbf{b}$ comparison with published literature results (MWCNTwater [24], $\mathrm{TiO}_{2}$ - water [25], $\mathrm{Al}_{2} \mathrm{O}_{3}$ - water [26])

sonication manifests the tendency for re-agglomeration, thereby resulting in a decrease in TC of nanofluids. Different researchers have suggested similar results, which are displayed in Fig. 3b. The presence of re-agglomeration in nanofluids by sonication beyond a critical point has also been confirmed microscopically [22,23]. Thus, based on Fig. 3 , the sonication time for subsequent synthesis of $h$-BN nanofluid having an EG/W (60/40) mixture ratio as base fluid is fixed as $240 \mathrm{~min}$.

The TC of $h$-BN nanofluids is measured at temperatures between 30 and $60{ }^{\circ} \mathrm{C}$ and for different volume fractions ranging from 0.5 to 2 vol\% $h$-BN. Figure 4 displays the TC enhancement calculated as per Eq. 4 for $h$ $\mathrm{BN}$ nanofluids at different temperatures.

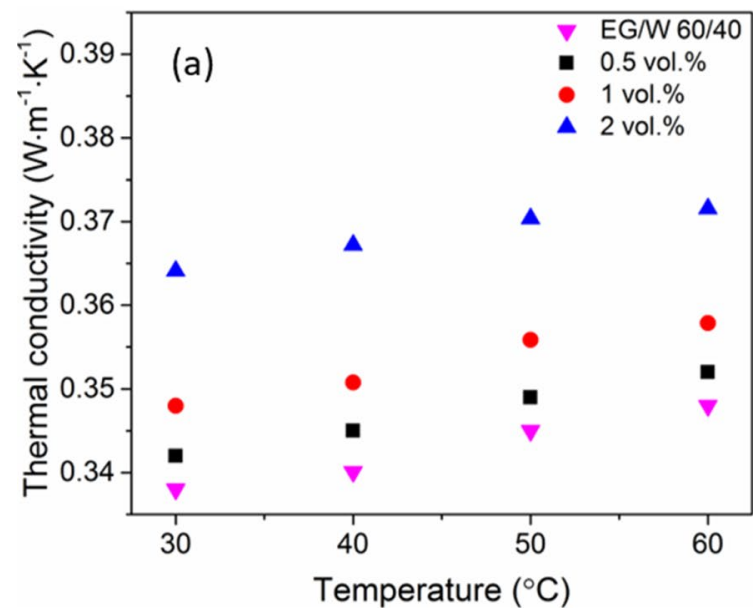

Thermal conductivty enhancement $=\left(\frac{k_{n f}-k_{b f}}{k_{b f}}\right) \times 100$

here $k_{n f}$ and $k_{b f}$ denote the TC of the nanofluid and base fluid in $\mathrm{W} \mathrm{m}^{-1} \mathrm{~K}^{-1}$

The results from Fig. 4 show an increasing TC enhancement with increasing volume concentrations, which is in agreement with many researchers $[27,28]$. The highest TC enhancement of $8 \%$ has been observed for 2 vol\% $h$ BN particle loading. Such an increase in TC enhancement can be related to the increased number of collisions due to Brownian motion between nanoparticles leading to enhanced TC [29]. Reports on the effect of temperature on TC of nanofluids are available [30, 31]. Yet, a common conclusive trend for the effect of temperature on the TC

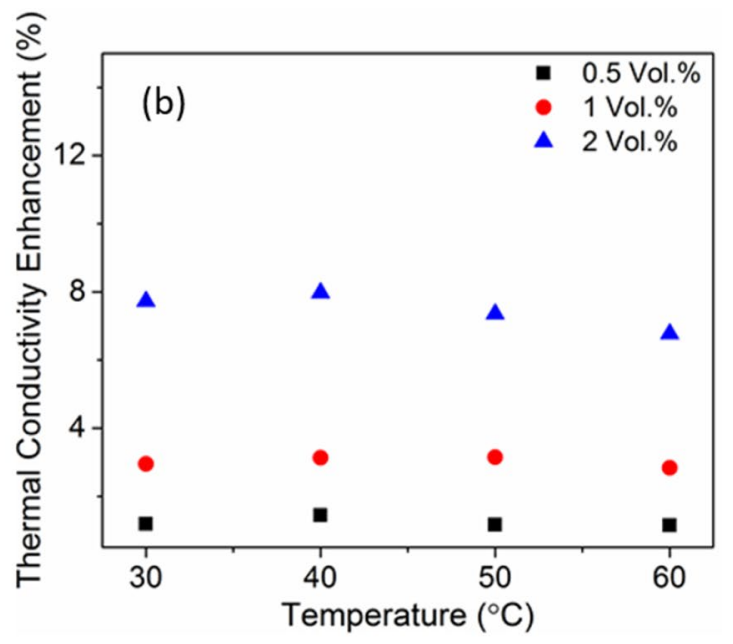

Fig. 4 Effect of temperature on the $\mathbf{a}$ absolute TC and the $\mathbf{b}$ TC enhancement of $h$-BN nanofluids for different particle concentrations 
enhancement has not reached. From Fig. 4 , it is observed that temperature has an insignificant impact on the TC enhancement depicting an almost independent kind of nature. For 2 vol\%, the TC enhancement is $7.7 \%$ at $30^{\circ} \mathrm{C}$, which when measured at $60^{\circ} \mathrm{C}$ is $6.7 \%$, a variation of only $0.1 \%$ from 30 to $60^{\circ} \mathrm{C}$. This kind of trend is similar to other particle loadings as well. Thus, the TC enhancement is almost constant with the increase in temperature, for all volume concentrations. This is because the absolute TC of $h$-BN nanofluids $\left(\mathrm{k}_{\mathrm{nf}}\right)$ and base fluid (EG/W 60/40) $\left(\mathrm{k}_{\mathrm{bf}}\right)$ increases by the same rate with respect to temperature, suggesting that the TC of $h$-BN nanofluids simply follow the TC of the base fluid EG/W 60/40. Similar conclusions were made by researchers like Timofeeva et al. [32], Suganthi et al. [33] and Yu et al. [34]. Timofeeva et al. [32] reported the temperature independent nature of TC enhancement with aqueous $\mathrm{Al}_{2} \mathrm{O}_{3}$ nanofluids, while Gallego et al. [35] concluded the near temperature independent nature of TC enhancement with $\mathrm{EG}$ based $\mathrm{Fe}_{3} \mathrm{O}_{4}$ and $\mathrm{Fe}_{2} \mathrm{O}_{3}$ nanofluids. Suganthi et al. [33] stated the following conclusion: the solvation layer forming around the nanoparticle's surface has a more ordered structure than the base fluid molecules and hence have higher TC. The TC of the solvation layer is known to contribute to the effective TC of nanofluid through liquid layering mechanism [36]. With the increase in temperature, the Brownian motion of nanoparticles also increases, which yields an increase in the effective TC due to their higher energy at high temperatures and micro-convection induced by the Brownian motion of nanoparticles [37, 38]. The decreases in the solvation layer thickness with the rise in temperature try to compensate for the effect of the increased Brownian motion leading to temperature invariance of the TC enhancement.
Having an understanding of the effects of volume concertation, shear rate, and temperature on the rheology of nanofluids is crucial for heat transfer applications, pumping power, etc. For the rheological study of EG/W $60 / 40$ based $h$-BN nanofluids, the viscosity is measured as a function of shear rate over the range from 0.612 to $122 \mathrm{~s}^{-1}$ between temperatures $30-60^{\circ} \mathrm{C}$. Figure 5 shows the flow curves for base fluid EG/W 60/40 measured at different temperatures. From Fig. 5 , it is clear that the base fluid (EG/W 60/40) exhibits Newtonian nature over the measured shear rates and temperatures.

The viscosity measurements for $h$-BN nanofluids having a particle concentration ranging from 0.5 to 2 vol\% are conducted over the same shear rate range and temperature as that conducted on the basefluid. Figure 6 shows the flow curves for $h$-BN nanofluids at different particle loadings (0.5-2 vol\%) measured between 30 and $60^{\circ} \mathrm{C}$. It has been observed that the apparent viscosity shows a slightly decreasing trend at the lower shear rates, which further maintains a constant viscosity towards the higher shear rates. This kind of behavior is visible for all the particle concentrations irrespective of the temperature. Considering the case of 2 vol\% $h$ BN nanofluids at $30^{\circ} \mathrm{C}$, the apparent viscosity drops by $13.4 \%$ over the shear rates from $0.612 \mathrm{~s}^{-1}$ to $24.5 \mathrm{~s}^{-1}$. This indicates that the viscosity displays a shear-thinning behavior (Non-Newtonian). Such shear thinning behavior possibly arises from the alignment of the nanoparticle clusters in the flow direction taking place with the increasing shear rate, thereby resulting in an initial decrease in viscosity. Other researchers have also observed similar behaviour [27] [17]. A constant viscosity is observed for shear rate beyond $24.5 \mathrm{~s}^{-1}$. This display of invariable viscosity at higher shear rates suggests the
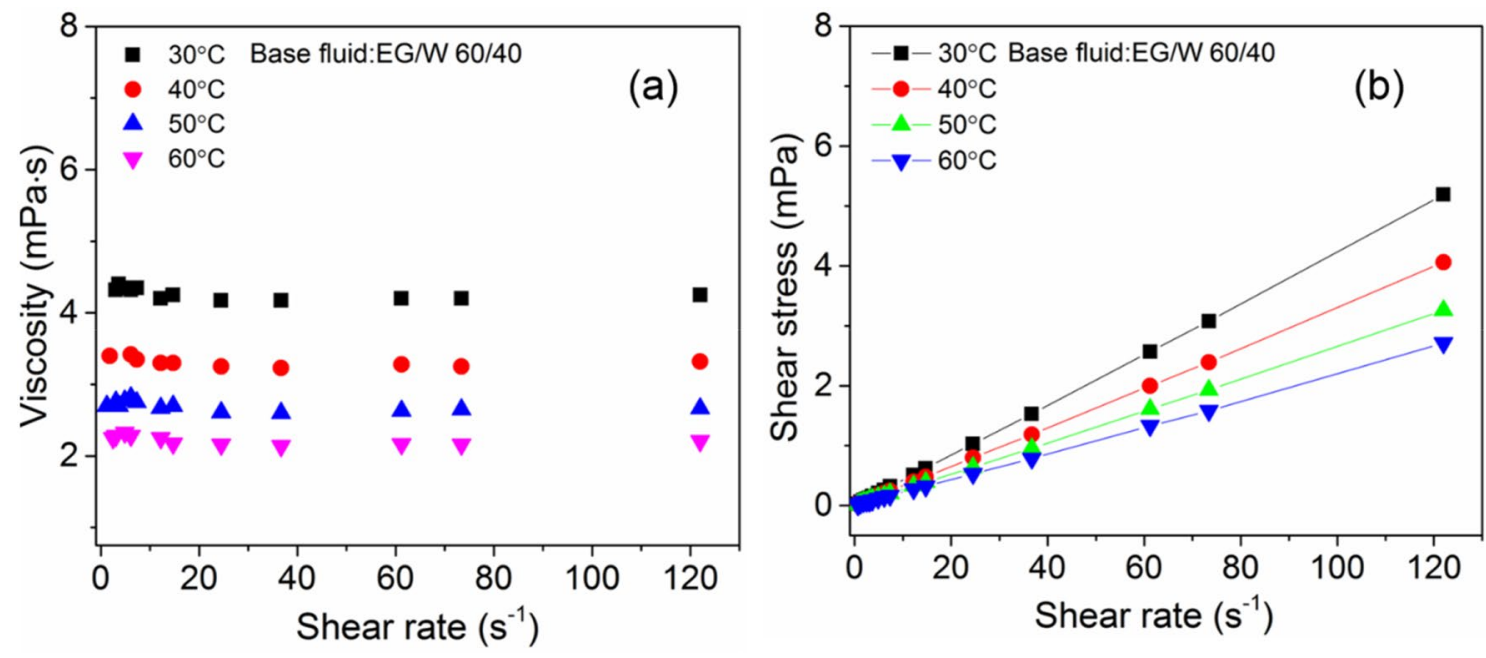

Fig. 5 a Viscosity versus shear rate $\mathbf{b}$ Shear stress versus shear rate of base fluid EG/W 60/40 at different temperatures 

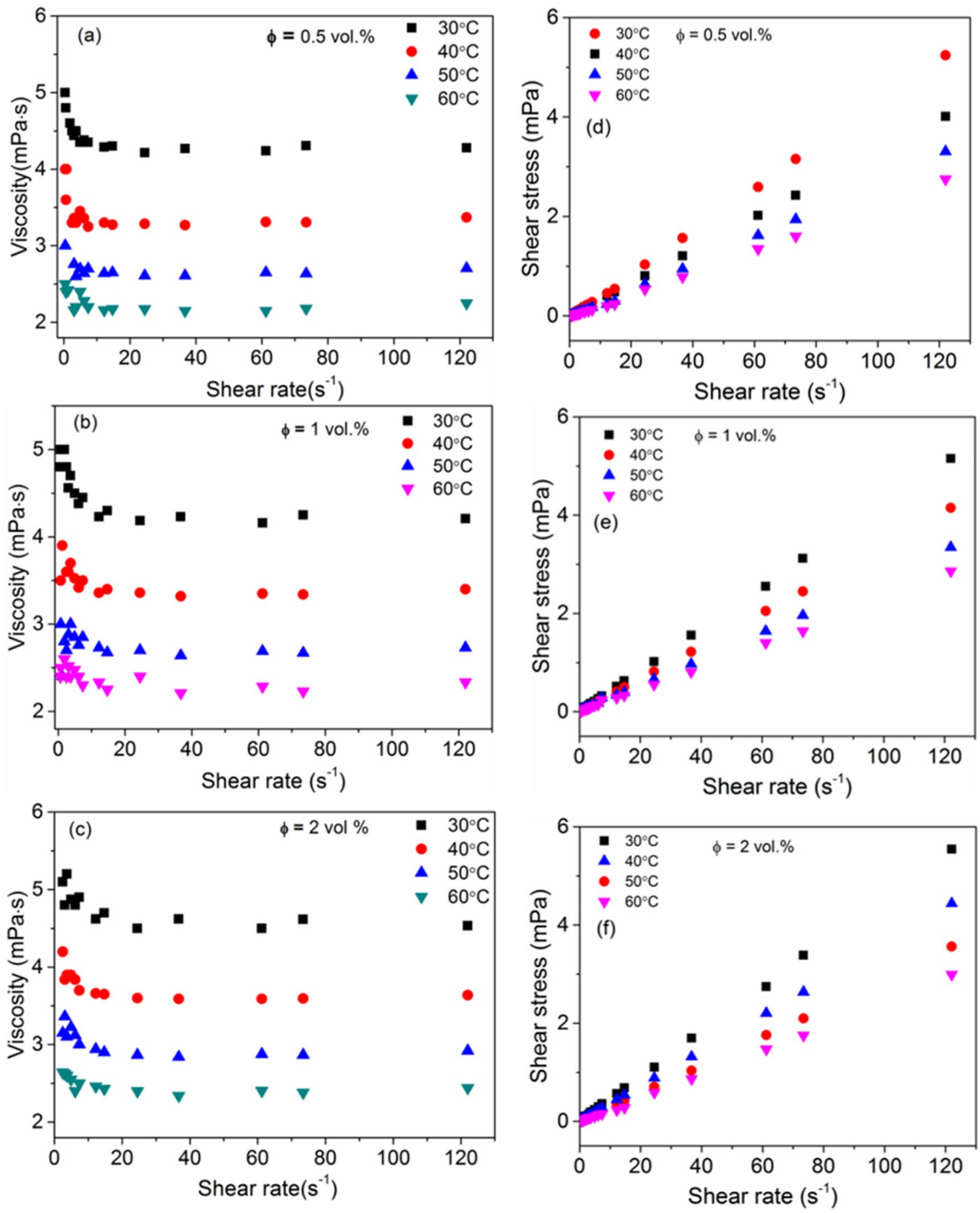

Fig. 6 Flow curves for nanofluids with (a, d) 0.5 vol \%, (b, e) 1 vol \% and (c, f) 2 vol \% of $h$ - BN particle loading at increasing temperatures

transformation to a more ordered kind of nanoparticle structure resulting in the Newtonian behaviour.

A decrease in viscosity of $h$-BN nanofluids at low shear rates is observed in Fig. 6, consequently displaying a non-Newtonian behavior with shear thinning characteristics. Several mathematical models like Casson
Model [39], Hershel-Buckley Model [40], Bingham Plastic model [41], and Power law model, etc. have been developed to describe the rheological behavior of fluids. Among them, the power-law model, proposed by Ostwald de Waele, is the most generalized model for non-Newtonian fluids. 


\subsection{Power law model}

The power law model, given by Eq. 5 , helps classify the nature of the fluid into Newtonian or non-Newtonian.

$\tau=K \dot{\gamma}^{n}$

here, $\dot{\gamma}$ and $\tau$ denote the shear rate (unit: $\mathrm{s}^{-1}$ ) and shear stress (unit: $\mathrm{mPa}$ ). The two parameters, consistency index ( $K$; unit: $\mathrm{mPa} \cdot \mathrm{s}^{\mathrm{n}}$ ) and flow index $n$ (unit: dimensionless), are used to describe the power law model. The consistency index is a measure of the average viscosity of the fluid, and the flow index denotes the degree at which the fluid displays the non-Newtonian behavior.

The power-law model expresses the viscosity $(\mu)$ for fluid as:

$\mu=K \dot{\gamma}^{n-1}$

Depending on the values of $n$, the fluids can be characterized as follows:

- For $n=1$, the viscosity shows an independent nature with respect to the shear rate and is known to follow a Newtonian behavior.

- For $n \neq 1$, the viscosity is a function of shear rate and follows a non-Newtonian behavior. Non-Newtonian fluids can be further categorized into shear thinning and shear thickening under increasing shear rates.

- If the magnitude of $n<1$, the fluid behaves as shear thinning or pseudoplastic. It is characterized by the apparent viscosity, which gradually decreases with the increasing shear rate.

- While for values of $n>1$, the apparent viscosity increases as the shear rate increases, and the fluid is known to have a shear thickening or dilatant behavior.

With non-Newtonian fluids, there usually exists a region at low or high shear rates where the viscosity is independent or nearly independent of shear rate forming a Newtonian plateau $\left(\eta_{0}\right.$ and $\left.\eta_{\infty}\right)$ and a section that exhibits strong shear rate dependence (shear thinning or shear thickening). The presence of the Newtonian plateau is also observed in the results for $h$-BN nanofluids.

In the present study, the shear thinning behavior of the $h$-BN nanofluids is characterized using the power law model. The parameters of the power law model can be determined from the plot of $L n$ versus $L n \gamma$, which is generally of the form of a straight line (Eq. 7). The intercept and slope of the straight line give the values of consistency index $(K)$ and flow index $(n)$.
$\operatorname{Ln}(\tau)=\operatorname{Ln}(K)+n \operatorname{Ln}(\dot{\gamma})$

Using Eq. (7), flow index and consistency index for $h$-BN nanofluids are obtained in the lower shear rate region for particle concentrations varying from 0.5 to 2 vol\% $h$-BN loading and at different temperatures. Figure 7 shows the logarithm plots for shear stress versus shear rate. Tables 2 and 3 displays the flow index and consistency index parameters obtained from fitting the Eq. 7. The power index values vary between 0.9091 and 0.9943 , suggesting the weak shear-thinning nature. Also, from Fig. 7, it is observed that both the particle concertation and temperature affect the consistency index of $h$-BN nanofluids. At a constant temperature, the consistency index of $h$-BN nanofluids increases with increasing particle concentration. And for a given particle concentration, the consistency index reduces as a result of temperature increment.

Nonetheless, it should be noted that in the present case, even though the power-law model provides an estimate of the shear-thinning nature, the subsequent Newtonian behavior that is observed at higher shear rates could not be predicted.

Another thing to note is the effect of temperature and nanoparticle volume fraction on the viscosity of $h$-BN nanofluid. The viscosity ratio is measured by taking the ratio of effective viscosity of nanofluid to the viscosity of the base fluid (in the present case, EG/W 60/40). Viscosity ratio is used to understand the effect of particle concentration on the viscosity of $h$-BN nanofluid. The viscosity of $h$-BN nanofluid obtained at a shear rate of $122 \mathrm{~s}^{-1}$ is observed to increases with the increasing nanoparticle concentration (Fig. 8). A maximum viscosity enhancement of $14.5 \%$ has been observed for 2 vol\% $h$-BN loading. The presence of nanoparticles increases the intermolecular forces, which cause resistance to flow, and thus the observed increased viscosity. Figure 9 shows the effect of temperature on the viscosity of EG/W 60/40 mixture and EG/W $60 / 40$ based $h$-BN nanofluids for different particle loadings. From the figure, it is clear that the viscosity of $\mathrm{EG} / \mathrm{W} 60 / 40$ reduces with the increase in temperature. The rise in temperature imparts energy to fluid molecules. As a result, the Brownian motion of molecules increases that weakens the intermolecular interactions. This results in a decreased fluid resistance in response to the shearing flow and a decline in viscosity is observed. This is an already established phenomenon for general fluids. The decrease in the viscosity occurs at a rate dependent on the fluid's intrinsic properties. In the case of EG/W 60/40 based $h$-BN nanofluids, a similar declining trend of viscosity with respect to temperature is evident. At $60^{\circ} \mathrm{C}$, the viscosity of 2 vol\% $h$-BN nanofluid shows a decrement of $49 \%$. It is noted that the change in nature of viscosity of $h$-BN nanofluids under the influence of temperature is not 

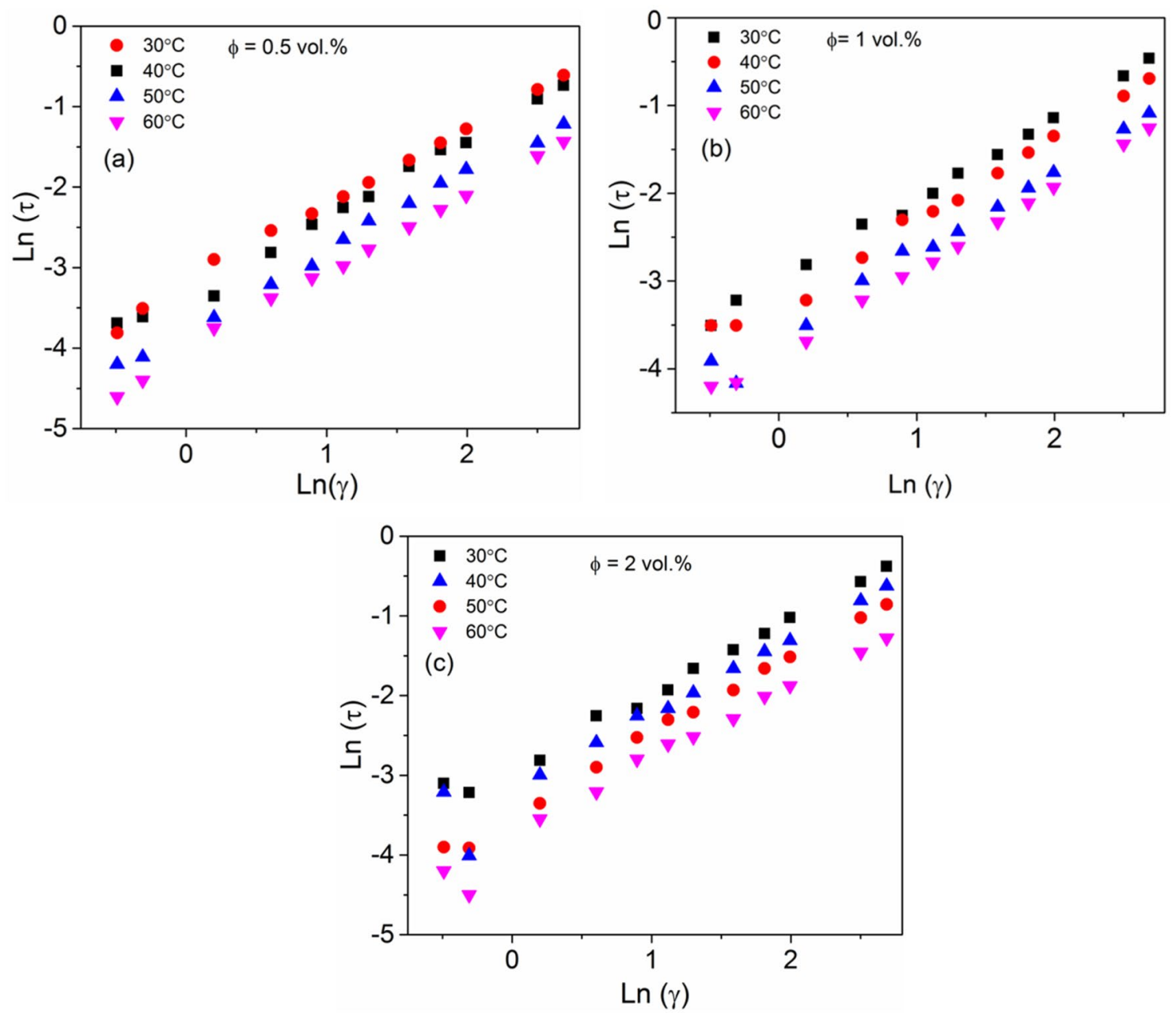

Fig. 7 Logarithmic plot of shear stress-shear rate for a $0.5 \mathrm{vol} \%$, b 1 vol \% and $\mathbf{c} 2$ vol \% at different temperatures

Table 2 Flow index values for $h$-BN nanofluids

\begin{tabular}{lllll}
\hline Vol \% & $30{ }^{\circ} \mathrm{C}$ & $40{ }^{\circ} \mathrm{C}$ & $50{ }^{\circ} \mathrm{C}$ & $60{ }^{\circ} \mathrm{C}$ \\
\hline 0.5 & 0.9721 & 0.9701 & 0.9652 & 0.9782 \\
1 & 0.9312 & 0.9259 & 0.9454 & 0.945 \\
2 & 0.9091 & 0.9525 & 0.9943 & 0.9805 \\
\hline
\end{tabular}

Table 3 Consistency index values for $h$-BN nanofluids

\begin{tabular}{lllll}
\hline Vol \% & $30{ }^{\circ} \mathrm{C}$ & $40{ }^{\circ} \mathrm{C}$ & $50{ }^{\circ} \mathrm{C}$ & $60{ }^{\circ} \mathrm{C}$ \\
\hline 0.5 & 0.0405 & 0.0352 & 0.0231 & 0.0175 \\
1 & 0.0497 & 0.0398 & 0.0263 & 0.0219 \\
2 & 0.0569 & 0.0411 & 0.0304 & 0.0217 \\
\hline
\end{tabular}

different from the behavior of the base fluid (EG/W 60/40), as observed in Fig. 9. Results from literature also report a prevalent downward trend in viscosity with an increase in temperature $[9,42]$.

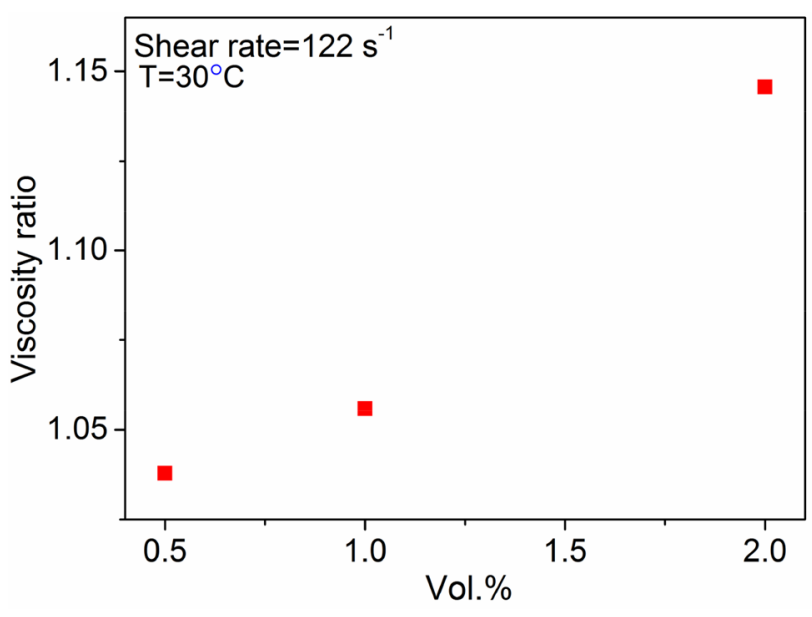

Fig. 8 Variation in viscosity of $h$-BN nanofluid with volume fraction at $\mathrm{T}=30^{\circ} \mathrm{C}$ 


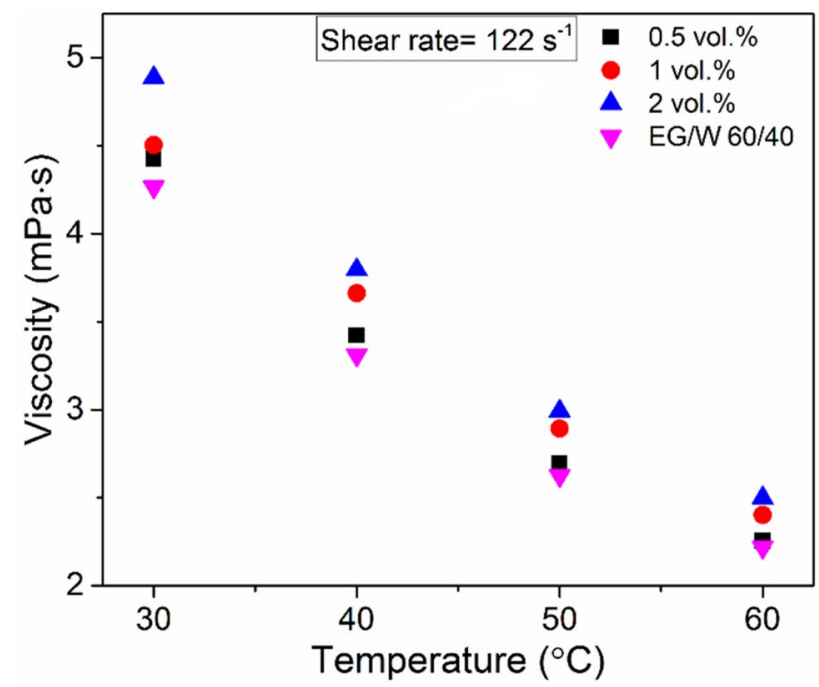

Fig. 9 Variation in viscosity of $h$-BN nanofluid (at shear rate $=122 \mathrm{~s}^{-1}$ ) with respect to increasing temperature for the different volume fraction of $h$-BN particle loading

\section{Comparison with other models}

For estimating the TC and viscosity of nanofluids, various classical and theoretical/analytical models have been proposed by different researchers $[32,43]$. In this view, commonly used classical models are selected from literature and compared with the present experimental results of $h$-BN nanofluids.

Hamilton-Crosser ( $\mathrm{H}-\mathrm{C})$ model [44] model given below, estimates the effective TC of nanofluid while taking into consideration the shape factor $(n)$ :

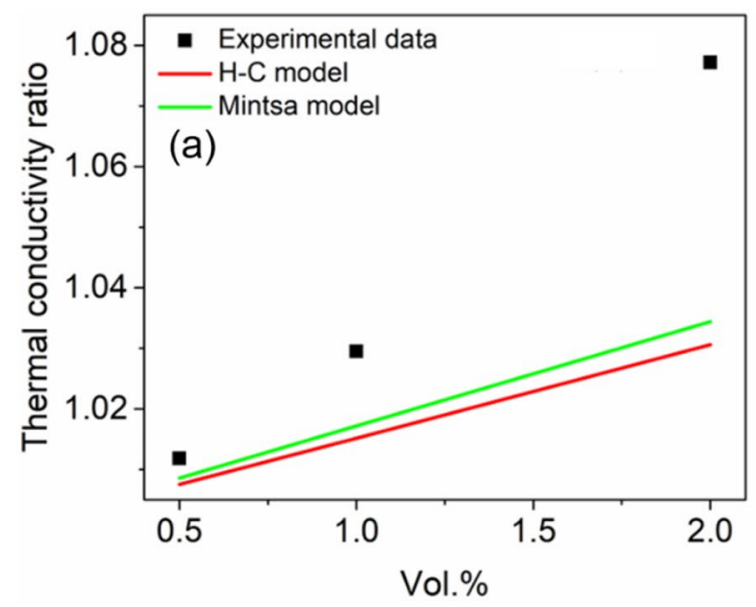

$\frac{k_{n f}}{k_{b f}}=\left[\frac{k_{p}+(n-1) k_{b f}-\phi(n-1)\left(k_{b f}-k_{p}\right)}{k_{p}+(n-1) k_{b f}+\phi(n-1)\left(k_{b f}-k_{p)}\right.}\right]$

here, $k_{p}$ represents the particle's TC. $\phi$ is the volume fraction. The shape factor $(n)$ is given by $n=\frac{3}{\psi}$ where $\psi$ defines the sphericity of the dispersed particle. In the case of spherical particles, $\psi=1$ while $\psi=0.5$ for cylindrical particles.

The Minsta model [45], developed based on the volume fraction of nanoparticles predicts the effective TC of nanofluids using the below relation:

$k_{n f}=k_{b f}(1.0+1.72 \phi)$

Einstein [46] and Batchelor [47] proposed theoretical models to estimate the effective dynamic viscosity of fluids as a function of dispersed particle concentration. While the Einstein model is effective for low particle concentration, the Batchelor model takes into effect the Brownian motion of the dispersed particles and its properties.

\subsection{Einstein model}

$\mu_{n f}=\mu_{b f}\left(1+2.5 \phi+6.5 \phi^{2}\right)$

\subsection{Batchelor model}

$\left.\mu_{n f}=\mu_{b f}(1+2.5 \phi)\right)$

Figure 10 shows the comparison of present experimental data with the results from the classical models. From Fig. 10, it can be said that these models underpredict the current experimental results. In the case of classical models, the parameters considered for predicting TC

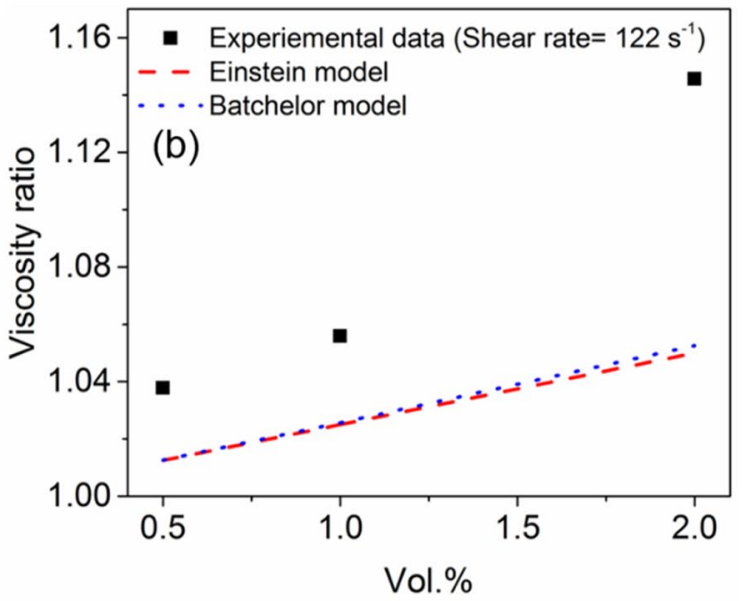

Fig. 10 Measured (a) TC ratio and (b) viscosity ratio for different particle loading of $h$-BN nanofluid in comparison with results from classical models 
and viscosity of fluids with suspension are limited and fail to include significant parameters like nanoparticle size, Brownian motion, nanoparticle aggregation, temperature, etc. This leads to a remarkable deviation from experimental results for nanofluids, as observed in Fig. 10. In this manner, it is significant to build up a relationship that will precisely predict the TC and viscosity of nanofluids at different temperatures and various working conditions.

\section{Proposed correlation}

Since the classical models are unable to predict the thermo-physical properties of nanofluids, a particular challenge for many researchers is to establish an appropriate relationship with a specific end goal to accurately predict the TC and viscosity of nanofluids at different levels of concentration and temperature.

Therefore, in this work, the experimental information has been utilized as relationship designs, and a connection has been accommodated anticipating the TC and viscosity with respect to nanoparticle concentration and temperature. The correlation equations are developed on the basis of present experimental results using nonlinear regression analysis. Curve fitting was performed using the Levenberg- Marquardt algorithm [48] to obtain the exact coefficient of the independent variables, volume concentrations $(\phi)$ and temperature (T). The following Eq. 11 predicts the TC and viscosity of $h$-BN nanofluids having EG/W $(60 / 40)$ mixture as base fluid for a given particle concentration $\left(0.5-2\right.$ vol\%) and temperature $\left(30-60^{\circ} \mathrm{C}\right)$.

$k_{n f}=0.363+(0.014 \times \phi)-\left(0.043 \times e^{-0.012 \times T}\right)$

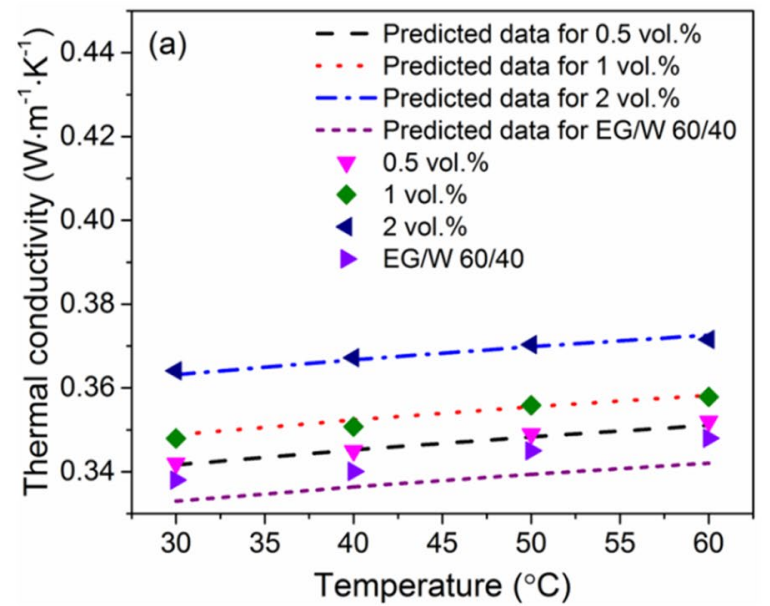

$\mu_{n f}=\left(37.74 \times T^{-0.43}\right)-\left(0.1 \times \phi^{2}\right)+(0.48 \times \phi)-4.41$

here, $k_{n f}$ denote the TC and $\mu_{n f}$ is the viscosity of nanofluids at temperature $(T)$ and volume concentrations $(\phi)$, respectively.

The developed correlation for TC and viscosity has an $R^{2}$ value of 0.9907 and 0.9929 . To test the potentiality of the proposed correlation (Eq. 11), it is compared with the experimental data. Figure 11 shows the present experimental results in comparison with the output from the developed correlation for $h$-BN nanofluids. The comparison shows good agreement between the results from the developed correlation and present experiment with a maximum deviation of $0.4 \%$ and $2.5 \%$ for TC and viscosity of $h$-BN nanofluids. Thus, the proposed correlation can predict the TC and viscosity of nanofluids at temperatures between 30 and $60^{\circ} \mathrm{C}$ and for volume concentration ranging from 0.5 vol\% to 2 vol\% $h$-BN loading.

The proposed correlation is used here to predict the optimal particle concentration for $h$-BN nanofluids, at which it displays the maximum thermo-physical performance. For that purpose, a commercially used heat transfer fluid such as DURATHERM 450 [49] is considered. DURATHERM 450 is a heat transfer fluid that is used for efficient heating and cooling process.

As per the datasheet available for DURATHERM 450, the $\mathrm{TC}$, and viscosity at $30^{\circ} \mathrm{C}$ is $0.143 \mathrm{~W} \cdot \mathrm{m}^{-1} \cdot \mathrm{K}^{-1}$ and $4.96 \mathrm{mPa} \cdot \mathrm{s}$. From the experimental results, the $h-\mathrm{BN}$ nanofluids with 2 vol\% particle loading show enhanced thermal properties in comparison with DURATHERM 450. The TC of $h$-BN nanofluids is higher than DURATHERM 450 , by $60.8 \%$, while the viscosity of DURATHERM 450 and $h$-BN nanofluids are almost comparable with DURATHERM 450 showing

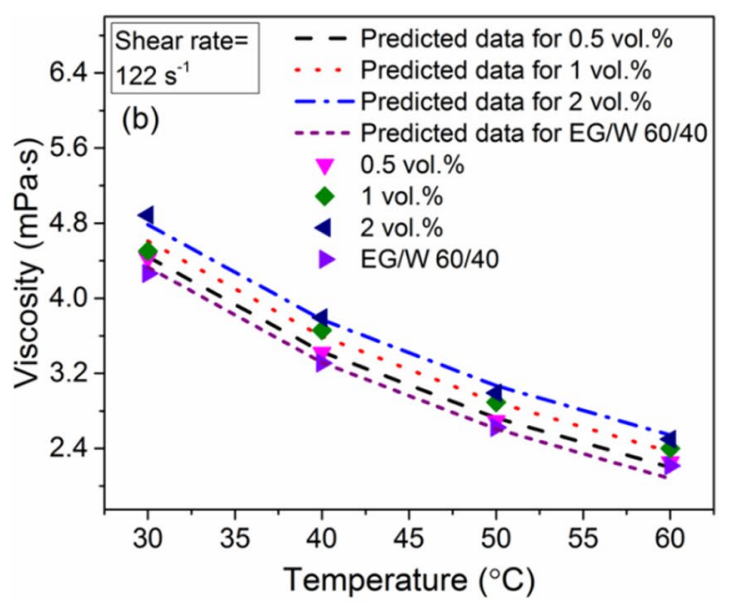

Fig. 11 Comparison of measured (a) TC and (b) viscosity of $h$-BN nanofluid with proposed correlation for different volume concentrations and temperature 
a slightly higher value by $3.3 \%$. Using the correlation, the estimated TC and viscosity for $h$-BN nanofluids at $2.5 \mathrm{vol} \%$ is $0.368 \mathrm{~W} \cdot \mathrm{m}^{-1} \mathrm{~K}^{-1}$ and $4.9 \mathrm{mPa} \cdot \mathrm{s}$. From the point of view of the application considered in this case, if $h$-BN nanofluids are used at $2.5 \mathrm{vol} \%$, one can achieve an increase of $61.4 \%$ in the TC as compared to DURATHERM 450, and at the same time, the difference in viscosity reduces to $1.22 \%$. Increasing the particle concentration beyond 2.5 vol\%, for instance, 3 vol\%, will show an increase in the TC, but the rise in viscosity will become more significant. This can create issues like pressure drop increase leading to the need for high pumping power. Also, nanofluids with high particle concentrations present concerns like sedimentation (caused by agglomeration), which can negatively affect its heat transfer characteristics-thereby compromising the total efficiency of the nanofluid. Therefore, the optimal particle loading of $h$-BN nanofluid can be considered at 2.5 vol\% for the current instance of the application. However, the correlation has to be first validated experimentally for further beyond particle concentrations. Another point to note is the temperature. Here, for the convenience of discussion, we have considered the TC and viscosity at a specific temperature. It would be more accurate if different range of temperature is taken into account for estimating the optimal particle concentration of nanofluids. Thus, rigorous experimental investigations will be required to test the relative influences and establish the general optimal correlation of particle loading.

Overall, the proposed correlation for estimating the TC and viscosity of nanofluid is valid for particle loadings 0.5 to 2 vol\% between temperatures $30-60^{\circ} \mathrm{C}$. The optimal particle concentration of $h$-BN nanofluid, for a specific application considered here as an example, is $2.5 \mathrm{vol} \%$. A further experimental study is required to investigate the optimal particle loading that will yield maximum thermophysical performance and, based on the results and factors, develop an optimal correlation of particle loading.

\section{Conclusions}

For a nanofluid, the choice of base fluid is crucial because the nanoparticles that cause the fluid properties to improve are dispersed in the base fluid. Common base fluids like water and ethylene glycol limit its applications in colder environments due to their high freezing point. Among all the EG/W mixture ratios, EG/W (60/40) possesses a high freezing point and thus is extensively used in cold climates. Therefore, in the present work, EG/W (60/40) has been chosen as the base fluid for the synthesis of $h-\mathrm{BN}$ nanofluids. The following conclusions were made based on the experimental results.
Using a two-step method, EG/W (60/40) based $h$-BN nanofluids, have been synthesized. The TC and viscosity of $h$-BN nanofluids were studied experimentally by varying the concentration of $h$-BN nanoparticles from 0.5 to 2 vol\% and temperature in the range from $30^{\circ} \mathrm{C}$ to $60^{\circ} \mathrm{C}$. The TC of $h$-BN nanofluids is found to increase with an increase in the particle concentration, and the maximum TC enhancement was observed to be $8 \%$ for 2 vol\% of $h$-BN loading. Interestingly, the temperature showed a negligible effect on the TC enhancement of $h$-BN nanofluids. The dynamic viscosity of $h$-BN nanofluids showed an increase with the increase in particle concentration, and maximum enhancement in the viscosity was observed to be $14.5 \%$ for 2 vol\% of $h$-BN loading. For all the volume concentrations, at lower shear rates, the $h$-BN nanofluids display a shear thinning behavior (non-newtonian), which might be due to the nanoparticle cluster alignment in the flow direction. With a further increase in the shear rate, a Newtonian nature has been observed for all the concentrations. Moreover, the dynamic viscosity of $h$-BN nanofluids decreases with the increase in temperature of the nanofluid. On the basis of experimental results, a new correlation is proposed that estimates the TC and viscosity of $h$-BN nanofluids with respect to the temperature and particle concentration.

The improvement in the thermo-physical properties of is the major highlight of nanofluid. Present work studies the thermo-physical properties of $h$-BN nanofluids only as a function of temperature and particle concentration. Further research is still required by taking into consideration the effect of aggregation, higher shear rates, and temperatures.

Acknowledgements This work has been sponsored by the grant no. DNRD/05/4003/NRB/248 of the Naval Research Board of DRDO, Government of India. The authors greatly acknowledge Prof. T.K Nandi from IIT Kharagpur for providing the experimental facilities to measure viscosity, respectively.

\section{Compliance with ethical standards}

Conflict of interest The authors declare that they have no conflict of interest.

\section{References}

1. Masuda H, Ebata A, Teramae K, Hishinuma N (2012) Alteration of thermal conductivity and viscosity of liquid by dispersing ultra-fine particles. Dispersion of $\mathrm{Al} 2 \mathrm{O} 3, \mathrm{SiO} 2$ and $\mathrm{TiO} 2$ ultrafine particles. Netsu Bussei 7:227-233. https://doi.org/10.2963/ jjtp.7.227

2. Eastman JA, Choi SUS, Li S, Yu W, Thompson LJ (2001) Anomalously increased effective thermal conductivities of ethylene glycol-based nanofluids containing copper nanoparticles. Appl Phys Lett 78:718-720. https://doi.org/10.1063/1.1341218 
3. Soltanimehr M, Afrand M (2016) Thermal conductivity enhancement of $\mathrm{COOH}$-functionalized MWCNTs/ethylene glycol-water nanofluid for application in heating and cooling systems. Appl Therm Eng 105:716-723. https://doi.org/10.1016/J.APPLT HERMALENG.2016.03.089

4. Li D, Xie W, Fang W (2011) Preparation and properties of copper-oil-based nanofluids. Nanoscale Res Lett 6:1-7. https://doi. org/10.1186/1556-276X-6-373

5. Hemmat Esfe M, Karimpour R, Abbasian Arani AA, Shahram J (2017) Experimental investigation on non-Newtonian behavior of Al2O3-MWCNT/5W50 hybrid nano-lubricant affected by alterations of temperature, concentration and shear rate for engine applications. Int Commun Heat Mass Transf 82:97-102. https:// doi.org/10.1016/j.icheatmasstransfer.2017.02.006

6. Yu W, Xie H, Chen L, Li Y (2010) Enhancement of thermal conductivity of kerosene-based $\mathrm{Fe} 3 \mathrm{O} 4$ nanofluids prepared via phase-transfer method. Colloids Surf A Physicochem Eng Asp 355:109-113. https://doi.org/10.1016/j.colsurfa.2009.11.044

7. Hamid KA, Azmi WH, Nabil MF, Mamat R, Sharma KV (2018) Experimental investigation of thermal conductivity and dynamic viscosity on nanoparticle mixture ratios of $\mathrm{TiO} 2-\mathrm{SiO} 2$ nanofluids. Int J Heat Mass Transf 116:1143-1152. https://doi. org/10.1016/j.ijheatmasstransfer.2017.09.087

8. Guo Y, Zhang T, Zhang D, Wang Q (2018) Experimental investigation of thermal and electrical conductivity of silicon oxide nanofluids in ethylene glycol/water mixture. Int J Heat Mass Transf 117:280-286. https://doi.org/10.1016/j.ijheatmasstrans fer.2017.09.091

9. Namburu PK, Kulkarni DP, Misra D, Das DK (2007) Viscosity of copper oxide nanoparticles dispersed in ethylene glycol and water mixture. Exp Therm Fluid Sci 32:397-402. https://doi. org/10.1016/j.expthermflusci.2007.05.001

10. Sundar LS, Singh MK, Sousa ACM (2013) Thermal conductivity of ethylene glycol and water mixture based $\mathrm{Fe} 3 \mathrm{O} 4$ nanofluid. Int Commun Heat Mass Transf 49:17-24. https://doi.org/10.1016/j. icheatmasstransfer.2013.08.026

11. Ramachandran $K$, Hussein $A M$, Kadirgama $K$, Ramasamy $D$, Azmi WH, Tarlochan F, Kadirgama G (2017) Thermophysical properties measurement of nano cellulose in ethylene glycol/water. Appl Therm Eng 123:1158-1165. https://doi.org/10.1016/j.applt hermaleng.2017.05.067

12. Yiamsawas $T$, Mahian O, Dalkilic AS, Kaewnai S, Wongwises $S$ (2013) Experimental studies on the viscosity of $\mathrm{TiO} 2$ and $\mathrm{Al} 2 \mathrm{O} 3$ nanoparticles suspended in a mixture of ethylene glycol and water for high temperature applications. Appl Energy 111:4045. https://doi.org/10.1016/j.apenergy.2013.04.068

13. Eshgarf $\mathrm{H}$, Afrand $\mathrm{M}$ (2016) An experimental study on rheological behavior of non-Newtonian hybrid nano-coolant for application in cooling and heating systems. Exp Therm Fluid Sci 76:221227. https://doi.org/10.1016/j.expthermflusci.2016.03.015

14. Bahrami M, Akbari M, Karimipour A, Afrand M (2016) An experimental study on rheological behavior of hybrid nanofluids made of iron and copper oxide in a binary mixture of water and ethylene glycol: non-Newtonian behavior. Exp Therm Fluid Sci 79:231-237. https://doi.org/10.1016/j.expthermfl usci.2016.07.015

15. Han W, Wang L, Zhang R, Ge C, Ma Z, Yang Y, Zhang X (2017) Water-dispersible boron nitride nanospheres with high thermal conductivity for heat-transfer nanofluids. Eur J Inorg Chem 2017:5466-5474. https://doi.org/10.1002/ejic.201700998

16. Ilhan B, Kurt M, Ertürk H (2016) Experimental investigation of heat transfer enhancement and viscosity change of $\mathrm{hBN}$ nanofluids. Exp Therm Fluid Sci 77:272-283. https://doi.org/10.1016/j. expthermflusci.2016.04.024

17. Michael M, Zagabathuni A, Ghosh S, Pabi SK (2018) Thermophysical properties of pure ethylene glycol and water-ethylene glycol mixture-based boron nitride nanofluids. J Therm Anal Calorim. https://doi.org/10.1007/s10973-018-7965-5

18. Carslaw HS, Jaeger JC (1959) Conduction of heat in solids, 2nd edn. Oxford University Press, London

19. Aparna Z, Ghosh S, Pabi SK (2017) Influence of container material on the heat transfer characteristics of nanofluids. Exp Heat Transf 30:302-315. https://doi.org/10.1080/08916 152.2016.1247122

20. ASHRAE (2009) Handbook-Fundamentals (SI Edition)

21. Williamson GK, Hall WH (1953) X-ray line broadening from filed aluminium and wolfram. Acta Metall 1:22-31. https://doi. org/10.1016/0001-6160(53)90006-6

22. Ruan B, Jacobi AM (2012) Ultrasonication effects on thermal and rheological properties of carbon nanotube suspensions. Nanoscale Res Lett 7:1-11. https://doi. org/10.1186/1556-276X-7-127

23. Michael M, Zagabathuni A, Sikdar S, Kumar S, Sudipto P (2020) Effect of dispersion behavior on the heat transfer characteristics of alumina nanofluid: an experimental investigation and development of a new correlation function. Int Nano Lett. https://doi. org/10.1007/s40089-020-00306-w

24. Asadi A, Alarifi IM, Ali V, Nguyen HM (2019) An experimental investigation on the effects of ultrasonication time on stability and thermal conductivity of MWCNT-water nanofluid: finding the optimum ultrasonication time. Ultrason Sonochem 58:104639. https://doi.org/10.1016/j.ultsonch.2019.104639

25. Sonawane SS, Khedkar RS, Wasewar KL (2015) Effect of sonication time on enhancement of effective thermal conductivity of nano TiO2-water, ethylene glycol, and paraffin oil nanofluids and models comparisons. J Exp Nanosci 10:310-322. https:// doi.org/10.1080/17458080.2013.832421

26. Buonomo B, Manca O, Marinelli L, Nardini S (2015) Effect of temperature and sonication time on nanofluid thermal conductivity measurements by nano-flash method. Appl Therm Eng 91:181190. https://doi.org/10.1016/j.applthermaleng.2015.07.077

27. Ijam A, Saidur R, Ganesan P, Moradi Golsheikh A (2015) Stability, thermo-physical properties, and electrical conductivity of graphene oxide-deionized water/ethylene glycol based nanofluid. Int J Heat Mass Transf 87:92-103. https://doi.org/10.1016/j.ijhea tmasstransfer.2015.02.060

28. Li X, Zou C, Qi A (2016) Experimental study on the thermophysical properties of car engine coolant (water/ethylene glycol mixture type) based SiC nanofluids. Int Commun Heat Mass Transf 77:159-164. https://doi.org/10.1016/j.icheatmasstrans fer.2016.08.009

29. Esfe MH, Saedodin S, Mahian O, Wongwises S (2014) Thermal conductivity of Al2O3/water nanofluids: measurement, correlation, sensitivity analysis, and comparisons with literature reports. J Therm Anal Calorim 117:675-681. https://doi. org/10.1007/s10973-014-3771-x

30. Agarwal R, Verma K, Agrawal NK, Singh R (2017) Sensitivity of thermal conductivity for Al2O3 nanofluids. Exp Therm Fluid Sci 80:19-26. https://doi.org/10.1016/j.expthermflusci.2016.08.007

31. Kumar N, Sonawane SS, Sonawane SH (2018) Experimental study of thermal conductivity, heat transfer and friction factor of $\mathrm{Al}_{2} \mathrm{O}_{3}$ based nanofluid. Int Commun Heat Mass Transf 90:1-10. https ://doi.org/10.1016/j.icheatmasstransfer.2017.10.001

32. Timofeeva EV, Gavrilov AN, McCloskey JM, Tolmachev YV, Sprunt S, Lopatina LM, Selinger JV (2007) Thermal conductivity and particle agglomeration in alumina nanofluids: experiment and theory. Phys Rev E Stat Nonlinear Soft Matter Phys 76:1. https:// doi.org/10.1103/PhysRevE.76.061203

33. Suganthi KS, Leela Vinodhan V, Rajan KS (2014) Heat transfer performance and transport properties of $\mathrm{ZnO}$-ethylene glycol and $\mathrm{ZnO}$-ethylene glycol-water nanofluid coolants. Appl Energy 135:548-559. https://doi.org/10.1016/j.apenergy.2014.09.023 
34. Yu W, Xie H, Li Y, Chen L, Wang Q (2012) Experimental investigation on the heat transfer properties of $\mathrm{Al}_{2} \mathrm{O}_{3}$ nanofluids using the mixture of ethylene glycol and water as base fluid. Powder Technol 230:14-19. https://doi.org/10.1016/j.powte c.2012.06.016

35. Pastoriza-Gallego MJ, Lugo L, Legido JL, Piñeiro MM (2011) Enhancement of thermal conductivity and volumetric behavior of Fe xOy nanofluids. J Appl Phys 110:014309. https://doi. org/10.1063/1.3603012

36. Keblinski P, Phillpot S, Choi SU, Eastman J (2002) Mechanisms of heat flow in suspensions of nano-sized particles (nanofluids). Int J Heat Mass Transf 45:855-863. https://doi.org/10.1016/S0017 $-9310(01) 00175-2$

37. Li CH, Peterson GP (2006) Experimental investigation of temperature and volume fraction variations on the effective thermal conductivity of nanoparticle suspensions (nanofluids). J Appl Phys 99:084314. https://doi.org/10.1063/1.2191571

38. Jang SP, Choi SUS (2004) Role of Brownian motion in the enhanced thermal conductivity of nanofluids. Appl Phys Lett 84:4316-4318

39. Casson N (1959) Rheology of disperse systems. Pergamon Press, London, $\mathrm{p} 84$

40. Herschel WH, Bulkley R (1926) Konsistenzmessungen von gummi-benzollösungen. Kolloid-Zeitschrift 39:291-300

41. Bingham EC (1922) Fluidity and plasticity. McGraw-Hill, New York

42. Aghahadi MH, Niknejadi M, Toghraie D (2019) An experimental study on the rheological behavior of hybrid Tungsten oxide
(WO3)-MWCNTs/engine oil Newtonian nanofluids. J Mol Struct 1197:497-507. https://doi.org/10.1016/j.molstruc.2019.07.080

43. James Clerk M (1881) A treatise on electricity and magnetism. Clarendon press, Oxford. https://doi.org/10.1017/CBO9780511 709333

44. Hamilton RL, Crosser OK (1962) Thermal conductivity of heterogeneous two-component systems. Ind Eng Chem Fundam 1:187-191. https://doi.org/10.1021/i160003a005

45. Mintsa HA, Roy G, Nguyen CT, Doucet D (2009) New temperature dependent thermal conductivity data for water-based nanofluids. Int J Therm Sci 48:363-371. https://doi.org/10.1016/j.ijthe rmalsci.2008.03.009

46. Einstein A (1906) A new determination of molecular dimensions. Ann Phys 19:289-306

47. Batchelor GK (1977) The effect of Brownian motion on the bulk stress in a suspension of spherical particles. J Fluid Mech 83:97. https://doi.org/10.1017/S0022112077001062

48. Marquardt DW (1963) An algorithm for least-squares estimation of nonlinear parameters.J Soc Ind Appl Math 11:431-441

49. DURATHERM Heat Transfer Fluids, (n.d.). durathermfluids.com/

Publisher's Note Springer Nature remains neutral with regard to jurisdictional claims in published maps and institutional affiliations. 